\title{
A crise brasileira: um olhar a partir da demanda agregada e do multiplicador keynesiano de gastos ${ }^{*}$
}

\author{
Cassiano José Bezerra Marques Trovão ${ }^{+}$
}

\section{Introdução}

O Brasil dos anos 2000 vivenciou uma retomada do crescimento econômico após duas décadas de baixo dinamismo. Apesar do ano de 2009, quando o PIB caiu 0,13\%, os indicadores apontavam um novo patamar para o crescimento da produção. No entanto, o que se observou após 2011 foi uma desaceleração do ritmo de crescimento e posteriormente uma forte queda de mais de 3\% do PIB nos anos de 2015 e 2016. É com o intuito de encontrar possíveis elementos explicativos para essa reversão que esse artigo faz sentido. Seu objetivo é apresentar uma interpretação para o movimento da atividade econômica no Brasil do período recente a partir da ótica da demanda agregada e do efeito multiplicador de gastos.

\section{Demanda agregada e o multiplicador de gastos}

Uma das principais identidades macroeconômicas presentes nas contas nacionais é a que se dá entre Produto (Y) e Demanda Agregada (DA). Se considerarmos produto tudo aquilo que é produzido no território nacional, independentemente da origem dos fatores de produção utilizados, então, pode-se definir Y como o Produto Interno Bruto (PIB).

Nas contas nacionais os componentes de DA aparecem da seguinte forma: consumo das famílias (C), gastos ou consumo do governo (G), exportações de bens e serviços não fatores $(X)$, importações de bens e serviços não fatores e Investimentos públicos e privados (I). Para o exercício analítico proposto, cujo suporte teórico parte dos ensinamentos de Keynes (1936), faz-se necessária a definição de algumas hipóteses básicas para facilitar a compreensão, sem que isso se distancie da realidade.

A primeira hipótese está baseada no argumento de que em uma economia com capacidade ociosa, a produção responde a estímulos de demanda no curto prazo. A segunda hipótese é que a elevação da produção é acompanhada por uma elevação do nível de emprego. A terceira hipótese é que a identidade $Y \equiv D A$, passa a ser vista como uma igualdade $(Y=D A)$ em que há um sentido de determinação que vai de DA para $Y .{ }^{1}$ Assim, pode-se definir:

$$
\begin{gathered}
Y=D A \\
D A=C+I+G+(X-M)
\end{gathered}
$$

logo,

$$
Y=C+I+G+(X-M)
$$

A partir da equação 3 percebe-se que, sob a hipótese de capacidade ociosa, Y (PIB) cresce quando os componentes de DA se elevam, com exceção das importações que representam vazamentos de renda, isto é, utilização de renda na aquisição (demanda) de bens e serviços produzidos fora do território nacional.

\footnotetext{
* O autor agradece os comentários de Fabrício Pitombo Leite e Juliana Bacelar de Araújo.

+ Professor do Departamento de Economia da Universidade Federal do rio Grande do Norte, e-mail: c_trovao@yahoo.com.br.

${ }^{1}$ A variação de estoques faz parte da cifra investimentos (I).
} 
Gráfico 1 - Utilização da Capacidade Instalada (UCI) na Indústria de transformação (\%) Brasil, 2003-2017

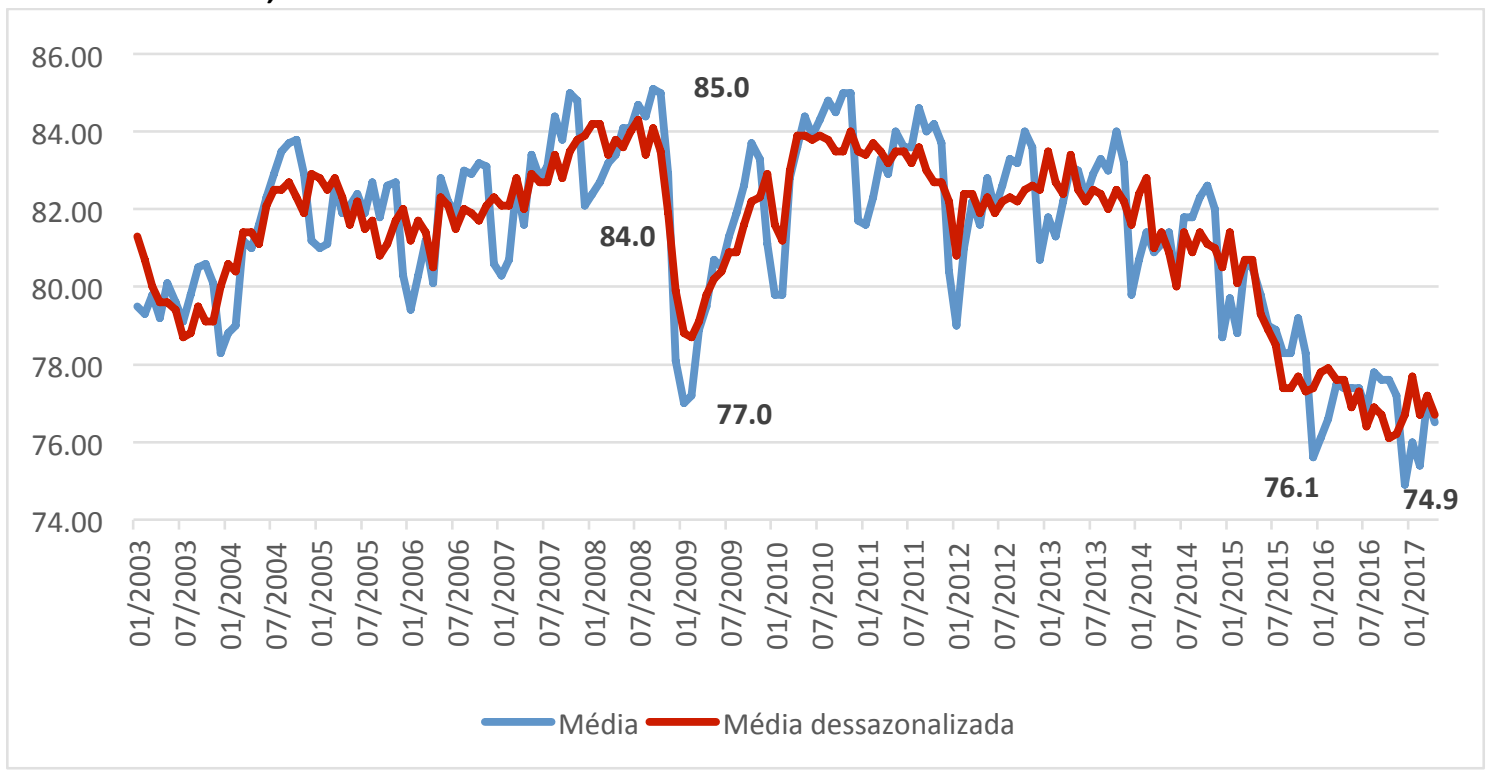

Fonte: CNI, Séries Históricas. Elaboração Própria.

O Gráfico 1 apresenta informações referentes à UCI na indústria de transformação brasileira a partir de 2003. O Brasil, no auge do crescimento econômico (2004-2008), chegou ao pico da série histórica, $85 \%$ em média. O período que compreende o reflexo da crise internacional para a economia doméstica (final de 2008 e início de 2009) indicou uma reversão rápida desse quadro, alcançando $77 \%$ para a média dessazonalizada. Com a recuperação econômica de 2010 a UCl voltou a subir. No entanto, o que se percebe a partir de então é que, com a desaceleração econômica e a posterior depressão (2015 em diante), a UCI voltou a cair atingindo em 2017 o menor valor de toda a série.

As evidências apontam que a economia brasileira passou a apresentar incrementos expressivos de capacidade ociosa após 2014. Assim, é razoável afirmar que a situação da economia brasileira é compatível com a hipótese de que, nessas condições, o produto e, consequentemente, o emprego podem responder a incentivos de demanda. A partir dessa ideia, torna-se fundamental avaliar a participação dos componentes de DA no PIB, sua evolução e contribuição ao crescimento econômico ${ }^{2}$ nesse período.

\footnotetext{
${ }^{2}$ Ver Fevereiro (2016).
} 
Tabela 1 - Composição do PIB segundo a ótica da Demanda Agregada (\% do PIB) Brasil, 2004-2017

\begin{tabular}{|c|c|c|c|c|c|c|c|c|c|}
\hline \multirow[b]{2}{*}{ Ano } & \multicolumn{3}{|c|}{ Consumo } & \multicolumn{3}{|c|}{ Formação Bruta de Capital } & \multirow[b]{2}{*}{ Exportação } & \multirow{2}{*}{$\begin{array}{c}\text { Importação } \\
(-)\end{array}$} & \multirow{2}{*}{$\begin{array}{l}\text { PIB a preços } \\
\text { de mercado }\end{array}$} \\
\hline & Total & Familias $^{a}$ & Governo & Total & Fixo & $\begin{array}{c}\text { Variação de } \\
\text { estoques }\end{array}$ & & & \\
\hline 2004 & 78,67 & 60,21 & 18,47 & 16,73 & 17,32 & 0,59 & 16,55 & 13,13 & 100 \\
\hline 2005 & 79,39 & 60,50 & 18,89 & 16,91 & 17,06 & 0,15 & 15,24 & 11,84 & 100 \\
\hline 2006 & 79,48 & 60,44 & 19,04 & 16,60 & 17,21 & 0,61 & 14,37 & 11,67 & 100 \\
\hline 2007 & 78,82 & 59,87 & 18,94 & 16,17 & 18,00 & 1,82 & 13,33 & 11,96 & 100 \\
\hline 2008 & 78,57 & 59,73 & 18,84 & 17,15 & 19,39 & 2,23 & 13,53 & 13,72 & 100 \\
\hline 2009 & 81,61 & 61,96 & 19,65 & 19,41 & 19,10 & $-0,31$ & 10,85 & 11,25 & 100 \\
\hline 2010 & 79,24 & 60,22 & 19,02 & 19,27 & 20,53 & 1,27 & 10,74 & 11,78 & 100 \\
\hline 2011 & 78,96 & 60,27 & 18,69 & 19,38 & 20,60 & 1,22 & 11,47 & 12,24 & 100 \\
\hline 2012 & 79,95 & 61,38 & 18,57 & 20,02 & 20,72 & 0,70 & 11,72 & 13,09 & 100 \\
\hline 2013 & 80,58 & 61,62 & 18,96 & 20,17 & 20,95 & 0,78 & 11,66 & 13,97 & 100 \\
\hline 2014 & 81,87 & 62,37 & 19,49 & 19,49 & 20,18 & 0,69 & 11,19 & 13,92 & 100 \\
\hline 2015 & 83,57 & 63,37 & 20,20 & 18,62 & 18,16 & $-0,45$ & 13,04 & 14,32 & 100 \\
\hline 10 trimestre $2016^{1}$ & 83,94 & 65,05 & 18,89 & 17,49 & 16,78 & $-0,71$ & 13,10 & 13,12 & 100 \\
\hline 20 trimestre $2016^{1}$ & 83,07 & 63,23 & 19,83 & 17,43 & 16,69 & $-0,74$ & 13,38 & 12,41 & 100 \\
\hline 3ㅇ trimestre $2016^{1}$ & 83,09 & 63,89 & 19,20 & 16,52 & 16,48 & $-0,03$ & 12,20 & 11,74 & 100 \\
\hline $4^{\circ}$ trimestre $2016^{1}$ & 86,56 & 63,92 & 22,65 & 17,85 & 15,63 & $-2,22$ & 11,35 & 11,31 & 100 \\
\hline $1^{\circ}$ Trimestre $2017^{1}$ & 82,24 & 62,94 & 19,29 & 14,19 & 15,59 & 1,40 & 12,07 & 11,31 & 100 \\
\hline
\end{tabular}

Fonte: IBGE - Sistema de Contas Naciona is Referência 2010. Elaboração: Ipea/Dimac/Gecon.

Dados anteriores a 1995 segundo antiga metodologia.

${ }^{a}$ Inclui consumo das instituições sem fins lucrativos ao serviço das famílias (ISFLSF).

1 Valores calculados a partir das Contas Nacionais Trimestrais.

Quanto aos dados da Tabela 1, o que chama atenção é a importância do consumo agregado (famílias mais governo), cuja participação passou de 78,67\% em 2004 para 86,56\% no último trimestre de 2016, maior patamar de todo o período analisado. Nesse segmento, o peso maior é o do consumo das famílias que passou de aproximadamente $60 \%$ para $63 \%$ no primeiro trimestre de 2017.

Os investimentos (Formação Bruta de Capital fixo - FBCF mais variação de estoques) tiveram sua participação ampliada até 2013. A partir de então, seu peso na composição de DA caiu sistematicamente até atingir em 2017 (10 trimestre) 14,2\%, valor muito abaixo dos 20,2\% de 2013. O período de crise, após o final de 2014, tem sido marcado por uma queda brusca na participação da FBCF, que se soma a variações de estoques negativas, com exceção do primeiro trimestre de 2017.

A demanda externa líquida, exportações menos importações, ampliou-se depois do primeiro trimestre de 2016. No entanto, o que parece ser um bom sinal, na realidade é o efeito que a queda do PIB e da renda nacional tem sobre as importações que perderam participação em ritmo superior à diminuição do peso das exportações no PIB, após 2015.

Esse cenário é confirmado pela análise das taxas de crescimento de todos os componentes de DA. A partir da Tabela 2 é possível verificar que: 1) o consumo das famílias, componente de maior peso, tem caído recorrentemente após 2014; 2) a FBCF, em 2014, apresentou um recuo de mais de $4 \%$, o que acabou sendo uma queda relativamente pequena frente às observadas para $2015(-14,1 \%), 2016(-10,17 \%)$, e para o 10 trimestre de 2017 ($3,74 \%)$; 3) as exportações cresceram durante o período da crise e somaram-se à queda expressiva das importações $(-14,3 \%$ e $-10,3 \%$ para 2015 e 2016, respectivamente) o que permitiu um aumento da participação líquida do componente da demanda externa no PIB (Ver Tabela 1); e 4) os gastos do governo em consumo também caíram após 2015, ainda que relativamente em menor intensidade. 
As decisões de políticas baseadas em cortes de gastos públicos para equilibrar as contas públicas, advogadas por setores do governo e da imprensa especializada e levadas a cabo a partir de 2015, nada mais representam que reduções de DA, o que, sob essas condições, contribuem para a redução de $Y^{3}$. Como visto na Tabela 2 , quando $Y$ cai, a arrecadação também cai, principalmente aquela que incide sobre movimentações comerciais. Assim, é de se esperar que reduções de $G$ provoquem quedas de $Y$, provocando diminuições na arrecadação, o que pode fazer com que essa política não surta o efeito esperado. É evidente que esse efeito não explica completamente o comportamento da queda da atividade econômica, mas deve ser levado em conta em um cenário em que os principais elementos de DA também estão em queda, isto é, consumo das famílias (-4\% e -4,24\% em 2015 e 2016, respectivamente) e FBCF $(-14,1 \%$ e $10,27 \%$ nos mesmos anos).

Tabela 2 - Taxa de crescimento dos componentes da demanda agregada, dos impostos e do PIB (em \% a.a.)

Brasil, $2004-2017$

\begin{tabular}{|c|c|c|c|c|c|c|c|c|c|c|}
\hline \multirow[b]{2}{*}{ Ano } & \multicolumn{3}{|c|}{ Consumo } & \multicolumn{3}{|c|}{ Formação Bruta de Capital } & \multirow[b]{2}{*}{ Exportação } & \multirow[b]{2}{*}{$\begin{array}{c}\text { Importação } \\
(-)\end{array}$} & \multirow{2}{*}{$\begin{array}{l}\text { Impostos } \\
\text { líquidos } \\
\text { sobre } \\
\text { produtos }\end{array}$} & \multirow{2}{*}{$\begin{array}{c}\text { PIB a } \\
\text { preços de } \\
\text { mercado }\end{array}$} \\
\hline & Total & Familias $^{a}$ & Governo & Total & Fixo & $\begin{array}{c}\text { Variação } \\
\text { de } \\
\text { estoques }\end{array}$ & & & & \\
\hline 2004 & 3,91 & 3,92 & 3,88 & 10,32 & 8,49 & 131,27 & 14,47 & 10,36 & 6,37 & 5,76 \\
\hline 2005 & 3,86 & 4,42 & 2,01 & $-2,50$ & 1,96 & $-132,73$ & 9,64 & 7,46 & 4,26 & 3,20 \\
\hline 2006 & 4,87 & 5,28 & 3,56 & 8,47 & 6,66 & 216,55 & 4,84 & 17,76 & 5,51 & 3,96 \\
\hline 2007 & 5,82 & 6,38 & 4,07 & 15,92 & 11,95 & 128,43 & 6,18 & 19,56 & 7,61 & 6,07 \\
\hline 2008 & 5,40 & 6,46 & 2,05 & 14,22 & 12,29 & 33,33 & 0,41 & 17,03 & 7,51 & 5,09 \\
\hline 2009 & 4,09 & 4,46 & 2,95 & $-14,50$ & $-2,13$ & $-121,78$ & $-9,25$ & $-7,60$ & $-0,28$ & $-0,13$ \\
\hline 2010 & 5,67 & 6,23 & 3,92 & 28,79 & 17,85 & $-654,57$ & 11,72 & 33,64 & 10,37 & 7,53 \\
\hline 2011 & 4,14 & 4,74 & 2,25 & 5,61 & 6,70 & $-12,19$ & 4,79 & 9,42 & 5,28 & 3,91 \\
\hline 2012 & 3,21 & 3,50 & 2,28 & $-2,57$ & 0,75 & $-58,81$ & 0,27 & 0,73 & 3,68 & 1,92 \\
\hline 2013 & 3,02 & 3,48 & 1,51 & 5,91 & 5,83 & 8,36 & 2,39 & 7,24 & 3,74 & 3,01 \\
\hline 2014 & 1,29 & 1,32 & 1,17 & $-4,40$ & $-4,48$ & $-2,10$ & $-1,05$ & $-1,05$ & 0,76 & 0,10 \\
\hline 2015 & $-3,30$ & $-4,00$ & $-1,05$ & $-18,33$ & $-14,10$ & $-142,14$ & 6,09 & $-14,32$ & $-7,02$ & $-3,85$ \\
\hline $2016^{1}$ & $n / d$ & $-4,25$ & $-0,56$ & $n / d$ & $-10,17$ & $n / d$ & 1,90 & $-10,29$ & $-6,39$ & $-3,59$ \\
\hline 10 trimestre $2017^{2}$ & $\mathrm{n} / \mathrm{d}$ & $-1,89$ & $-1,32$ & $\mathrm{n} / \mathrm{d}$ & $-3,74$ & $\mathrm{n} / \mathrm{d}$ & 1,87 & 9,75 & $-0,84$ & $-0,35$ \\
\hline
\end{tabular}

A Tabela 3 traz informações, até 2015 , sobre o comportamento da contribuição de cada um dos componentes de DA ao crescimento do PIB. Alguns apontamentos: 1) no período de crescimento (2004-2010) da economia brasileira, observaram-se significativas contribuições, primeiramente do consumo das famílias e, posteriormente, da FBCF (componentes de DA intimamente relacionados à dinâmica interna da economia nacional); 2) no período de desaceleração e, posteriormente no início da crise (2015) houve recorrentes diminuições na contribuição desses dois componentes, sendo que a FBCF, já em 2014, passou a contribuir negativamente para o crescimento do PIB; 3 ) as exportações, componente externo de DA, também reduziram sua contribuição, revertendo essa tendência apenas em 2015.

Sob a perspectiva Keynesiana, o investimento, ao lado do consumo, aparece como elemento central da dinâmica econômica pois possibilita a ampliação do estoque de capital e, portanto, da riqueza. No entanto, como apontou Keynes (1936), uma das principais características de uma economia monetária é que essa variável é bastante instável, o que não se mostrou diferente no Brasil do período analisado. Não se pode deixar de notar que a instabilidade e queda de I e a redução do consumo das famílias são os principais responsáveis pelo comportamento do PIB na crise.

\footnotetext{
${ }^{3}$ Ver a contribuição de G ao PIB de 2015 na Tabela 3.
} 
Por fim, como demonstrou Keynes (1936), o consumo do governo poderia ser um instrumento anticíclico que reduziria ou suavizaria os movimentos instáveis de DA associados às características específicas de $\mathrm{I}$. No entanto, o que se observou no Brasil foi um comportamento relativamente pró-cíclico de $\mathrm{G}$, apresentando-se como um elemento de redução da atividade econômica e de agravamento da crise, especialmente quando a política de cortes de gastos passou a fazer parte da realidade econômica brasileira pós $2015^{4}$.

Tabela 3 - Contribuição ao Crescimento do PIB - Metodologia IPEA ${ }^{\mathrm{a}}$

Brasil, 2004-2015

\begin{tabular}{|c|c|c|c|c|c|c|c|c|}
\hline \multirow[b]{2}{*}{ Ano } & \multicolumn{3}{|c|}{ Consumo } & \multicolumn{3}{|c|}{ Formação Bruta de Capital } & \multirow[b]{2}{*}{ Exportação } & \multirow{2}{*}{$\begin{array}{c}\text { PIB a } \\
\text { preços de } \\
\text { mercado }\end{array}$} \\
\hline & Total & Familias & Governo & Total & Fixo & $\begin{array}{l}\text { Variação de } \\
\text { estoques }\end{array}$ & & \\
\hline 2004 & 2,80 & 2,08 & 0,71 & 1,16 & 1,05 & 0,11 & 1,80 & 5,76 \\
\hline 2005 & 2,53 & 2,20 & 0,34 & $-0,62$ & 0,02 & $-0,65$ & 1,29 & 3,20 \\
\hline 2006 & 2,73 & 2,12 & 0,60 & 0,83 & 0,42 & 0,41 & 0,40 & 3,96 \\
\hline 2007 & 3,59 & 2,93 & 0,66 & 1,84 & 1,42 & 0,42 & 0,64 & 6,07 \\
\hline 2008 & 3,36 & 3,06 & 0,30 & 1,71 & 1,26 & 0,45 & 0,02 & 5,09 \\
\hline 2009 & 3,36 & 2,78 & 0,58 & $-2,67$ & 0,20 & $-2,87$ & $-0,81$ & $-0,13$ \\
\hline 2010 & 3,03 & 2,42 & 0,61 & 3,65 & 2,12 & 1,53 & 0,84 & 7,53 \\
\hline 2011 & 2,71 & 2,33 & 0,38 & 0,81 & 0,96 & $-0,15$ & 0,39 & 3,91 \\
\hline 2012 & 2,34 & 1,92 & 0,41 & $-0,45$ & 0,13 & $-0,58$ & 0,03 & 1,92 \\
\hline 2013 & 1,95 & 1,71 & 0,24 & 0,89 & 0,85 & 0,05 & 0,17 & 3,02 \\
\hline 2014 & 0,78 & 0,52 & 0,25 & $-0,53$ & $-0,74$ & 0,21 & $-0,10$ & 0,15 \\
\hline 2015 & $-1,85$ & $-1,72$ & $-0,13$ & $-2,72$ & $-1,99$ & $-0,73$ & 0,73 & $-3,85$ \\
\hline
\end{tabular}

Fonte: IBGE - Sistema de Contas Nacionais Referência 2010. Elaboração: Ipea/Dimac/Gecon.

${ }^{a}$ Pesos no ano anterior ( $\left.\mathrm{t}-1\right) \mathrm{x}$ taxa de crescimento $(\mathrm{t})$ da demanda por bens de origem nacional

Com base na Tabela 3, o que se observou foi que a diminuição do ritmo de crescimento e posterior queda acentuada dos componentes de DA, especialmente da FBCF e do consumo das famílias, provocaram uma redução drástica de $\mathrm{Y}$.

A teoria keynesiana permite que se proponha diversas formas de análise para a relação exposta na equação 3 . Assim, este estudo propõe que se analise complementarmente essa relação a partir de dois modelos simples.

O primeiro parte da hipótese de que, com exceção de $C$, os outros componentes de DA são autônomos, isto é, que não dependem de $\mathrm{Y}$, então tem-se que: $I=I_{A} ; G=G_{A} ; X=$ $X_{A} ; M=M_{A}$, onde $I_{A}, G_{A}, X_{A}$ e $M_{A}$ são todos componentes autônomos ${ }^{5}$. Assim, tem-se que:

$$
Y=C+I_{A}+G_{A}+X_{A}-M_{A}
$$

No caso do consumo, pode-se afirmar que $C$ é uma função direta de $Y$, como se segue:

$$
C=c Y
$$

onde, $\mathrm{C}$ é o consumo gregado e $\mathrm{cY}$ é parte do consumo que depende da renda $(\mathrm{Y})$, isto é, da multiplicação de $c$ (propensão a consumir) por Y (renda ミ produto).

Após algumas transformações algébricas e substituindo (5) em (4) pode-se chegar à:

\footnotetext{
${ }^{4}$ Ver Serrano e Summa (2015).

${ }^{5}$ Mais à frente, serão relaxadas duas hipóteses referentes à $Y$ e à $M$, que passarão a depender, respectivamente, da renda disponível (renda líquida de impostos) e, da própria renda (importações como proporção de Y).
} 


$$
Y=\frac{1}{(1-c)}\left[I_{A}+G_{A}+X_{A}-M_{A}\right]
$$

O termo $\frac{1}{(1-c)}$ é o que se chama na literatura keynesiana de multiplicador de gastos. ${ }^{6}$ De acordo com Rodrigues e Bastos (2010) e Bastos et al (2015), pode-se calcular a parcela da renda destinada ao consumo (c) de duas formas: 1) sob a hipótese Kaleckiana de que os trabalhadores gastam tudo que ganham, a propensão a consumir $\left(c_{1}\right)$ pode ser definida pela relação entre o total da remuneração dos empregados, extraída das contas nacionais ${ }^{7}$, e o PIB; 2) sob a hipótese de que todo o consumo das famílias é induzido pela renda, essa variável, a que se chama $\left(c_{2}\right)$, pode ser definida pela razão entre o valor do consumo das famílias agregado e o $\mathrm{PIB}^{8}$.

A diferença entre as duas formas de mensuração é considerável. Enquanto representação da renda a ser transformada em consumo, a primeira atribui um peso elevado para a fonte de renda advinda do mercado de trabalho. Um primeiro desafio à sua utilização está relacionado ao peso que outras fontes de renda assumem enquanto possível fonte de recursos para o consumo. No caso brasileiro, rendas advindas da proteção social (Previdência Social, Benefício de Prestação Continuada - BPC, no âmbito da Lei Orgânica da Assistência Social - LOAS) e dos programas de transferência direta de renda, como o Bolsa Família, representam uma grande parcela da renda das famílias. ${ }^{9}$ Outro desafio advém do elevado peso que é dado à renda do trabalho, por conta dos impactos que as oscilações no âmbito do mercado de trabalho podem trazer para a determinação de "c".

\section{Gráfico 2 - Multiplicadores de gastos construídos a partir da propensão a consumir definida pela massa de salários/PIB (c1) e do consumo agregado das famílias/PIB (c2). Brasil, 2004-2017}

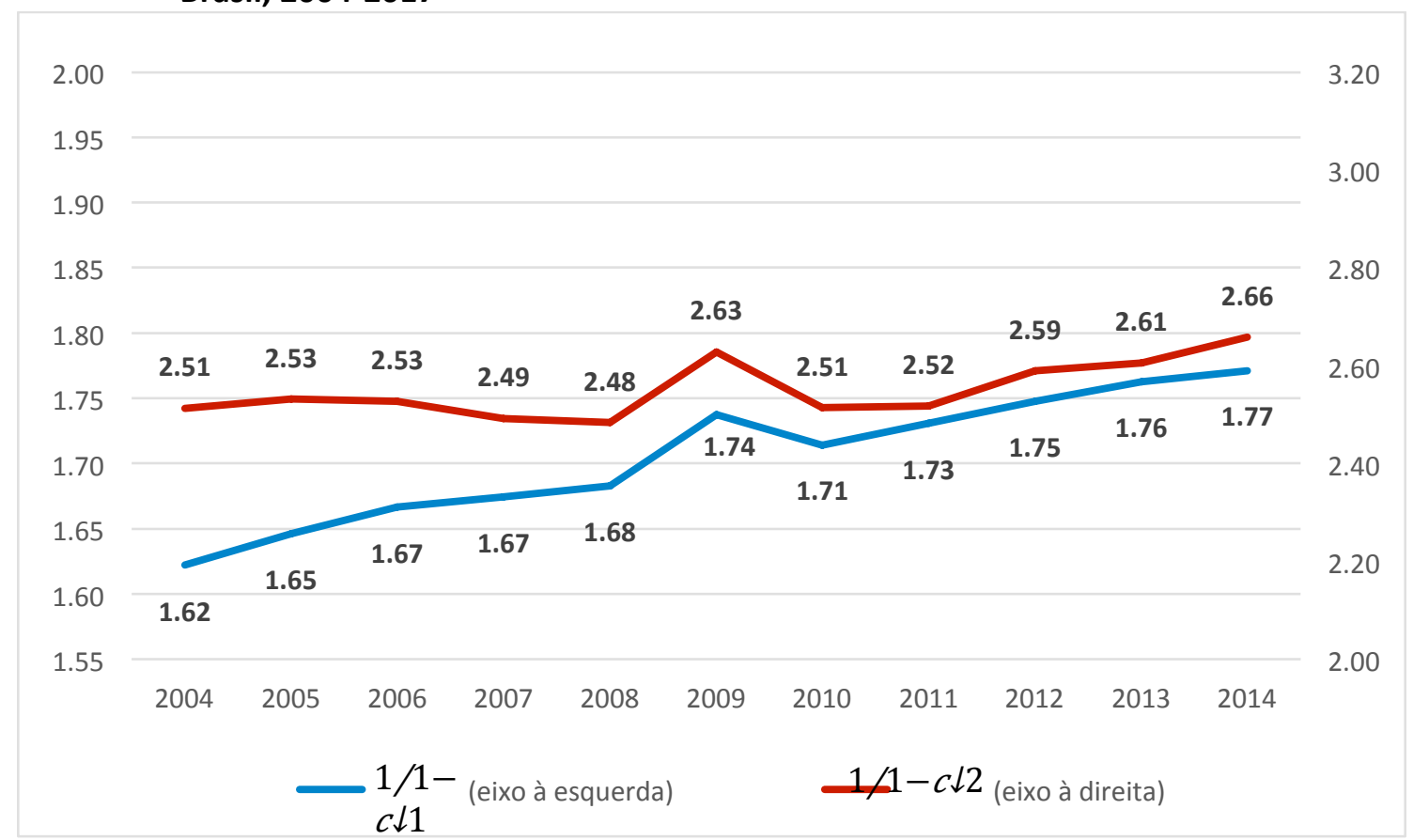

Fonte: IBGE, Sistema de Contas Nacionais e Contas Nacionais Trimestrais. Elaboração Própria.

\footnotetext{
${ }^{6}$ Ver Kahn (1931).

${ }^{7}$ O último ano disponível é 2014.

${ }^{8}$ Outra forma de construção da PMC, com dados da Pesquisa de Orçamento Familiar do IBGE, pode ser vista em Leite (2015).

${ }^{9}$ Ver Hoffmann (2013).
} 
A segunda forma de mensuração pode ser mais representativa e próxima da realidade brasileira pois considera a propensão a consumir como sendo a parcela do consumo agregado das famílias no PIB, o que leva em conta não apenas a renda do trabalho, mas todas as formas de renda (Ver gráfico 2). ${ }^{10}$

Por qualquer uma, a evolução do valor do multiplicador indica uma tendência de ampliação no período de 2004 a 2015. Entre o final de 2015 e o primeiro trimestre de 2016, $\frac{1}{1-c_{2}}$ apresenta uma queda, seguida por uma ligeira alta até o quarto trimestre de 2016, recuando novamente no primeiro trimestre de 2017.

À primeira vista, a redução do multiplicador entre o início de 2016 e o início de 2017 poderia se mostrar favorável, pois se o multiplicador de gastos cai durante a queda dos componentes de DA, isso significa que o efeito sobre a produção e, consequentemente sobre o emprego, deve ser relativamente menor. Seguindo essa lógica, a queda expressiva do produto deveria, nesse período, ter sido ainda mais acentuada caso a propensão a consumir $\left(\boldsymbol{c}_{2}\right)$ não tivesse declinado entre o primeiro trimestre de $2016\left(c_{2}=0,651\right)$ e o primeiro trimestre de $2017\left(c_{2}=0,629\right){ }^{11}$ No entanto, deve-se destacar que essa queda do multiplicador aumenta a possibilidade de a recuperação da economia se dar de forma mais lenta, devido ao impacto relativamente menor que os gastos autônomos (DA) passam a ter sobre o próprio nível de atividade e emprego.

Relaxando-se algumas das hipóteses feitas para a definição da equação 6 , pode-se apresentar o consumo enquanto uma função da renda disponível (Yd) e as importações como função do nível da atividade econômica (Y). Assim, tem-se o seguinte:

$$
C=c(Y d) \quad(7)^{12}
$$

sendo,

$$
Y d=Y-T
$$

onde,

$\mathrm{T}$ = arrecadação de impostos líquida de transferências

Ao considerar que a arrecadação de impostos assume a forma de carga tributária, isto é, que ela representa a parcela da renda/produto $(\mathrm{Y})$ que é destinada ao pagamento de tributos, pode-se dizer então que:

$$
T=t Y
$$

onde,

$t$ = carga tributária, definida pela relação entre arrecadação tributária e o PIB.

Ademais, ao considerar que as importações também são uma função do nível de atividade econômica $(\mathrm{Y})$, tem-se que:

$$
M=m Y
$$

\footnotetext{
${ }^{10}$ Parte do consumo possui caráter autônomo e é impulsionada pelo crédito às famílias.

11 Quanto menor a propensão a consumir menor é o multiplicador (Ver Tabela 1 e Gráfico 2).

12 A preocupação do artigo é mais a tendência do multiplicador e menos o seu tamanho; assim, optouse por não se estimar a parcela do consumo autônomo. O cálculo do multiplicador mais amplo está baseado na definição de $c_{2}$. A respeito da literatura que trata do tamanho do multiplicador, ver Pires (2012).
} 
onde,

$m$ = propensão a importar, definida pela relação entre valor das importações agregadas e o PIB.

Substituindo as equações (10) e (7) em (3), pode-se obter o seguinte:

$$
Y=c(Y d)+I+G+X-m Y
$$

Considerando que I, G e X continuam sendo componentes de gastos autônomos e combinando a equação (10) a (9) e posteriormente agregando-a à equação (12), pode-se escrever a nova condição que define a identidade $Y \equiv D A$ como:

$$
Y=c(Y-t Y)+I_{A}+G_{A}+X_{A}-m Y
$$

Após algumas transformações algébricas pode-se definir a equação final como:

$$
Y=\frac{1}{1-c(1-t)+m}\left(I_{A}+G_{A}+X_{A}\right)
$$

Os resultados para o cálculo do termo $\frac{1}{1-c(1-t)+m}$ aparecem no Gráfico 3. Vale salientar que se assumiu a hipótese de que as cargas tributárias de 2016 e 2017 ( $1^{\circ}$ trimestre) foram iguais às de 2015. Os resultados indicam que a introdução de " $\mathrm{t}$ " e de " $\mathrm{m}$ " no modelo, como era esperado, alteram o patamar do multiplicador sensivelmente de mais de 2,5 (Gráfico 2) para menos de 1,5 (Gráfico 3), o que representa os efeitos dos impostos e das importações enquanto diminuições de demanda agregada ou vazamentos de renda.

\section{Gráfico 3 - Crescimento do PIB e Multiplicador de gastos para economia aberta e com governo, Brasil, 2004-2017.}

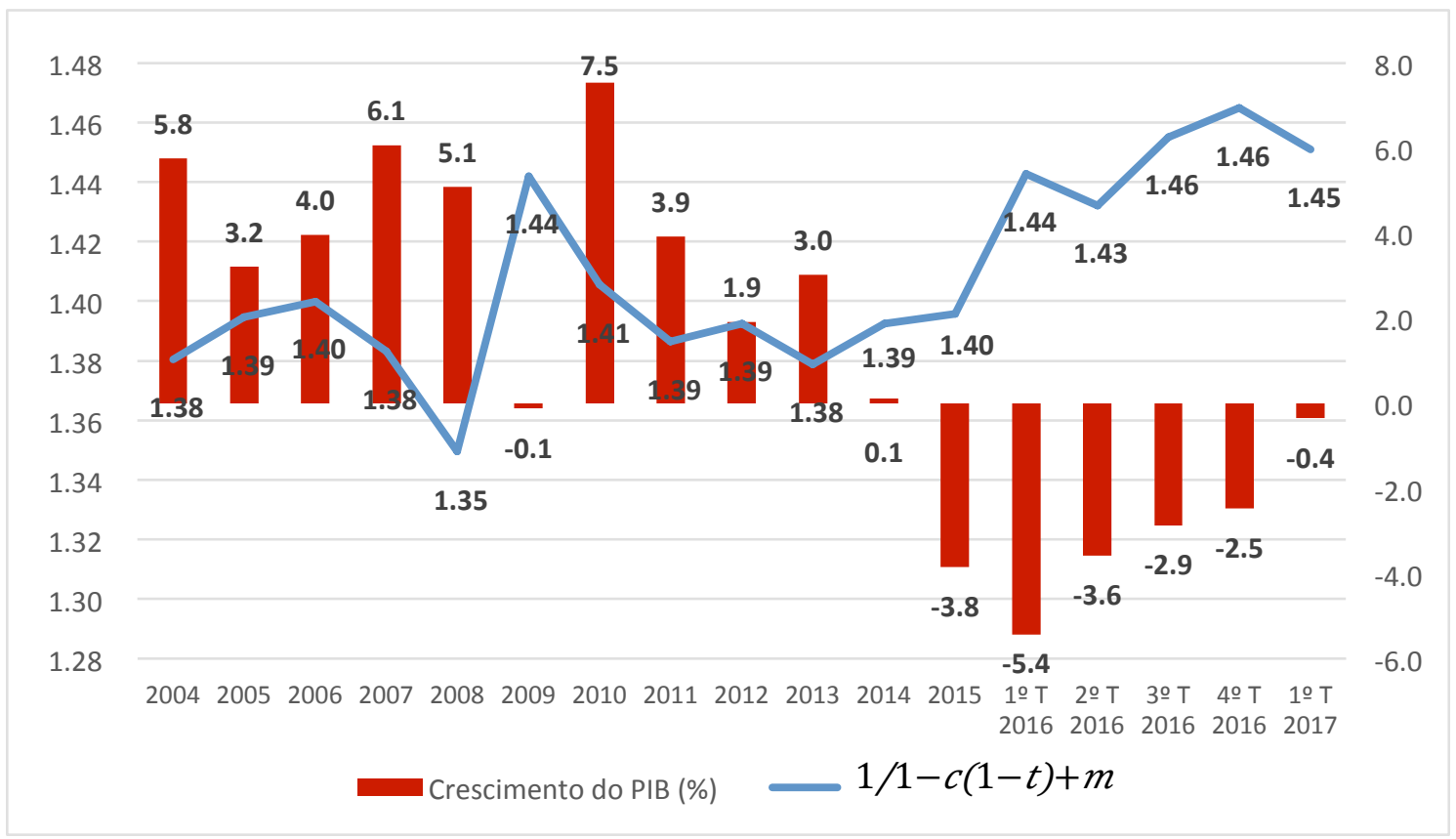

Fonte: IBGE, SCN e Ministério da Fazenda, Secretaria da Receita Federal. Elaboração Própria.

O que chama mais a atenção é a tendência. De 2004 a 2013, o multiplicador se manteve estável, com exceção dos anos de queda brusca do produto em 2009 (aumento do multiplicador) e forte recuperação em 2010 (queda do multiplicador), o que parece seguir uma lógica anticíclica. Comparativamente ao cálculo elaborado apenas com a propensão a consumir definida a partir da parcela do consumo agregado das famílias no PIB $\left(\frac{1}{1-c_{2}}\right)$, esse novo 
multiplicador $\left(\frac{1}{1-c(1-t)+m}\right)$ apresentou um comportamento similar, por conta da importância da propensão ao consumo e do fato de a propensão a importar não se ter alterado (ver tabela 1) e da hipótese de manutenção da carga tributária. ${ }^{13}$

O multiplicador assumiu, depois de 2014, um comportamento anticíclico ${ }^{14}$, aumentando seu patamar em momentos de queda da atividade econômica e diminuindo no momento em que a atividade econômica poderia esboçar uma redução do ritmo de queda ou estabilização (10 trimestre de 2017). Isso implica que esse comportamento recente do multiplicador pode carregar desafios à recuperação da atividade econômica porque, no momento em que se exige uma resposta dos componentes de DA e do impulso dado pelo efeito multiplicador, essa parece ficar relativamente mais limitada.

\section{Conclusão}

Os dados apontam que a crise socioeconômica tomou proporções que impedem qualquer prognóstico de que esse cenário se reverterá no curto prazo. A queda dos componentes da demanda agregada em uma economia com capacidade ociosa elevada e em trajetória ascendente demostra a dificuldade do processo de recuperação. E a evolução do multiplicador de gastos no Brasil, parece não colaborar para uma rápida recuperação.

Certamente a recuperação da economia nacional passa pela elevação dos componentes de DA, isto quer dizer do consumo das famílias, dos investimentos e dos gastos do Governo. As exportações e a agricultura nacional estão fazendo seu papel, mas certamente são insuficientes para movimentar uma economia como a brasileira.

Os efeitos macroeconômicos combinados entre a queda dos componentes de DA e o efeito multiplicador anticíclico trazem desafios complexos para a retomada da atividade econômica brasileira e do emprego. Dada a elevada capacidade ociosa da economia nacional, a recuperação de DA é necessária para uma retomada do crescimento de forma sustentada.

Uma alternativa para a retomada do crescimento nacional e regional exigirá soluções para: 1) o comportamento dos investimentos privados em um ambiente econômico e político de grandes incertezas; 2 ) a retomada do consumo das famílias em um cenário de elevado desemprego e de endividamento; 3) o papel do Estado e de seu orçamento enquanto mecanismo de reação a problemas associados à insuficiência de demanda agregada.

No entanto, o debate atual quanto ao papel do Estado tem se pautado pela lógica de corte dos gastos, que incluem a PEC dos gastos e a reforma previdenciária, além de medidas que favorecem a redução de custos das empresas, o que inclui a reforma trabalhista. Tanto essas reformas como a medida mais explícita de impor um teto ao crescimento das despesas públicas por 20 anos são medidas que deprimem DA. O que vai de encontro a tudo que foi exposto nesse trabalho. O caminho para o Brasil sair da depressão e voltar a crescer certamente não está na redução dos componentes de DA. Ademais, se o pressuposto das medidas de corte de gastos é que o orçamento público melhore, então se assume que a arrecadação não tem qualquer relação com o desempenho do produto, o que parece não corresponder à realidade. Se não houver uma alteração de rumo na economia orientada por uma gestão da política econômica que busque a superação do problema de insuficiência de demanda agregada e a ampliação do crescimento econômico, pode-se assistir a uma aceleração da deterioração das condições socioeconômicas em diversas dimensões.

\footnotetext{
${ }^{13}$ Um possível aumento da carga tributária levaria a uma queda ainda maior do multiplicador.

${ }^{14}$ Qazizada e Stockhammer (2014) e Auerbach e Gorodnichenko (2011) encontram resultados similares para países avançados e da OCDE.
} 


\section{Referências}

Auerbach, A. J. e Gorodnichenko, Y. (2011) "Fiscal Multipliers in Recession and Expansion", NBER WP $\mathrm{n}^{\circ} 17447$.

Bastos, C. P., Rodrigues, R. e Lara, F. M. (2015) “As finanças públicas e o impacto fiscal entre 2003 e 2012: 10 anos de governo do Partido dos Trabalhadores", Ensaios FEE, 36(3), p. 675-706.

Fevereiro, J. B. (2016) "Decomposição da taxa de crescimento do PIB pelo lado da demanda: uma metodologia alternativa", Nota Técnica, Carta de Conjuntura IPEA, n. 30.

Hoffmann, R. (2013) "Transferências de renda e desigualdade no Brasil (1995-2011)", In: T. Campello e M. Neri (eds.) Programa Bolsa Família: uma década de inclusão $e$ cidadania, Brasília: IPEA, p. 207-216.

Kahn, R. F. (1931) "The Relation of Home Investment to Unemployment", The Economic Journal, 41(162), pp. 173-198.

Keynes, J.M. (1936) The General Theory of Employment, Interest and Money. São Paulo: Nova Cultural.

Leite, F. P. (2015) "Como o grau de desigualdade afeta a propensão marginal a consumir? Distribuição de renda e consumo das famílias no Brasil a partir dos dados das POF 2002-2003 e 2008-2009", Economia e Sociedade, 24(3), p. 617-650.

Qazizada, W. e Stockhammer, E. (2014) "Government spending multipliers in contraction and expansion", Post Keynesian Economics Study Group Working Paper, n. 1404.

Pires, M. C. C. (2012) "Controvérsias recentes sobre multiplicadores fiscais", V Encontro Internacional $d a \quad A K B$ São Paulo, Disponível em <http://www.akb.org.br/upload/130820121605557370_Manoel\%20Carlos\%20de\%20C astro\%20Pires.pdf>. Acessado em 18/01/2018.

Rodrigues, R. e Bastos, C. (2010) “Análise recente das finanças públicas e da política fiscal do Brasil", III Encontro da Associação Keynesiana Brasileira, São Paulo, Disponível em <http://www.ppge.ufrgs.br/akb/encontros/2010/49.pdf>. Acessado em 20/09/2017.

Serrano, F. e Summa, R. (2015) "Demanda agregada e a desaceleração do crescimento econômico brasileiro de 2011 a 2014" Center for Economic and Policy Research (CEPR), Washington, DC. 